\title{
Hydrophobic vs. hydrophilic: ionic competition in remacemide salt structures
}

\section{Additional Details of the Structure Analyses}

1. Molecular Structure and Conformational Analysis

In structures 1 and 7, there is a widening of the $\mathrm{C}(5)-\mathrm{C}(3)-\mathrm{C}(11)$ angle (relative to the mean tetrahedral angle, Table 4) that can be attributed to the Thorpe-Ingold effect ${ }^{1}$ i.e. a geminal steric repulsion between the $\mathrm{C}(5)$-aromatic ring and the $\mathrm{C}(11)$-methylene group. When the angle between one pair of groups on a tetrahedral carbon is increased in this way, the bond angle between the other pair of groups generally decreases. This is the case here, with a narrowing of angle $\mathrm{N}(2)-\mathrm{C}(3)-\mathrm{C}(4)$ (Table 4 manuscript).

The Thorpe-Ingold effect at atom C(3) is also operative in structures 2-6, but this time geminal steric repulsion between the $\mathrm{C}(5)$-aromatic ring and the $\mathrm{C}(4)$-methyl group results in a widening of angle $\mathrm{C}(5)-\mathrm{C}(3)-\mathrm{C}(4)$ and a concomitant narrowing of $\mathrm{N}(2)-\mathrm{C}(3)-\mathrm{C}(11)$. The orientation of the aromatic ring $\left(\tau_{3} / \tau_{3}\right.$, Table 4 manuscript) would appear to be significant in directing the widening effect, with the molecules having a phenyl $\mathrm{C}-\mathrm{H}$ [ortho to atom $\mathrm{C}(5)]$ in close contact with either the $\mathrm{C}(4)$-methyl group (2-6) or the $\mathrm{C}(11)$-methylene $(\mathbf{1}$ and 7): e.g. in $\mathbf{1}, \mathrm{H}(6) \bullet \bullet \bullet \mathrm{H}(11) \mathrm{B}=2.23 \AA$ and $\mathrm{H} 6 \bullet \bullet \bullet C(11)=$ $2.58 \AA$ ( $c f .2 .40 \AA$ and $2.90 \AA$ for the sum of the $\mathrm{H}, \mathrm{H}$ and $\mathrm{H}, \mathrm{C}$ van der Waals radii, ${ }^{2}$ respectively). These close contacts lend credence to the notion that the orientation of the $\mathrm{C}(5)$-aromatic ring makes a significant contribution to the geminal steric repulsion and, through this, directs the Thorpe-Ingold effect at atom $\mathrm{C}(3)$.

The Thorpe-Ingold effect is also observed at atom $\mathrm{C}(11)$ in structures 1-7 [mean angle $\left.\mathrm{C}(3)-\mathrm{C}(11)-\mathrm{C}(12)=114.7^{\circ}\right]$ and at atom $\mathrm{C}(1)$ in structure $1\left[\mathrm{~N}(1)-\mathrm{C}(1)-\mathrm{C}(2)=115.5(2)^{\circ} ; c f\right.$. $107.0(2)^{\circ}$ to $111.1(2)^{\circ}$ in $\mathbf{2 - 7}$, where $\mathrm{N}(1)$ is protonated].

There are a number of other notable observations to be made concerning the bonding and interactions of the $\mathrm{C}(5)$-aromatic ring in the structures of $\mathbf{1}$ to $\mathbf{7}$. For example, the internal ring angle $\mathrm{C}(6)-\mathrm{C}(5)-\mathrm{C}(10)$ is significantly narrower (by $1.9^{\circ}$, on average) than the ideal $s p^{2}$ geometry. This is in keeping with expectations based on reports of structural substituent effects in benzene derivatives. ${ }^{3}$ Distortion of $s p^{2}$ geometry is also evidenced by a small degree of pyramidalisation of the $\mathrm{C}(5)$-atom [apparent from the fact that atom $\mathrm{C}(3)$ is displaced from the ring plane by $0.034(2)-0.232(2) \AA$ ] Comparable distortions of the aromatic $s p^{2}$ geometry at atom $\mathrm{C}(12)$ are also evident.

In all molecules (except $\mathbf{5 a}$ and $\mathbf{5 b}$ ), there is close contact between the $\mathrm{C}(5)$-aromatic ring and the carbonyl O-atom $[\mathrm{C}(5) \bullet \bullet \bullet \mathrm{O}(1)=2.899(17)-3.191(3) \AA ; c f .3 .22 \AA$ for the sum of the van der Waals radii $^{2}$ ]. The corresponding range of distances in the geometry-optimized structures (footnote 'e' of Table 
Electronic Supplementary Information

4 manuscript) is somewhat longer at $3.29-3.47 \AA$, suggesting that the close contacts observed in the crystal structures are energetically unfavorable. It seems probable that the $\mathrm{C}(5) \bullet \bullet \bullet \mathrm{O}(1)$ close contacts are subsidiary to the more favorable intermolecular $\mathrm{H}$-bond contacts involving the $\mathrm{O}(1)$-atom and the associated amide $\mathrm{N}-\mathrm{H}$.

\section{References}

1. Bassindale, A. The Third Dimension in Organic Chemistry; John Wiley and Sons: Chichester, UK, 1984

2. Bondi, A. J. Phys. Chem., 1964, 68, 441-51.

3. Domenicano, A. in Accurate Molecular Structures, Domenicano, A. and Hargittai, I. (Eds), Oxford University Press: Oxford, 1992. 
Electronic Supplementary Information

\section{Crystal structure of Remacemide 1}

Within the $\mathrm{H}$-bond chains (parallel to the $c$-axis), there are repeating $\mathrm{N}-\mathrm{H} \bullet \bullet \bullet \mathrm{O}=\mathrm{C} \mathrm{H}$-bonds $[d=$ 2.00(3), $D=2.873(2) \AA, \theta=174(2)^{\circ}$; Figure 4 manuscript]. Graph set analysis describes this chain of H-bonds as C(4), purely a first level pattern (unitary motif), and the only H-bond observed in this structure.

When viewed parallel to the crystallographic $c$-axis, the interdigitating 1-D chains of H-bonded molecules form layers (with ef contacts between chains). Further ef contacts are observed between the layers, as each benzyl aromatic ring interacts with two nearest neighbor phenyl rings: one from within the same layer, and one from that adjacent. All of the above pairwise interactions are shown the Figure $\underline{\text { ESI1. }}$

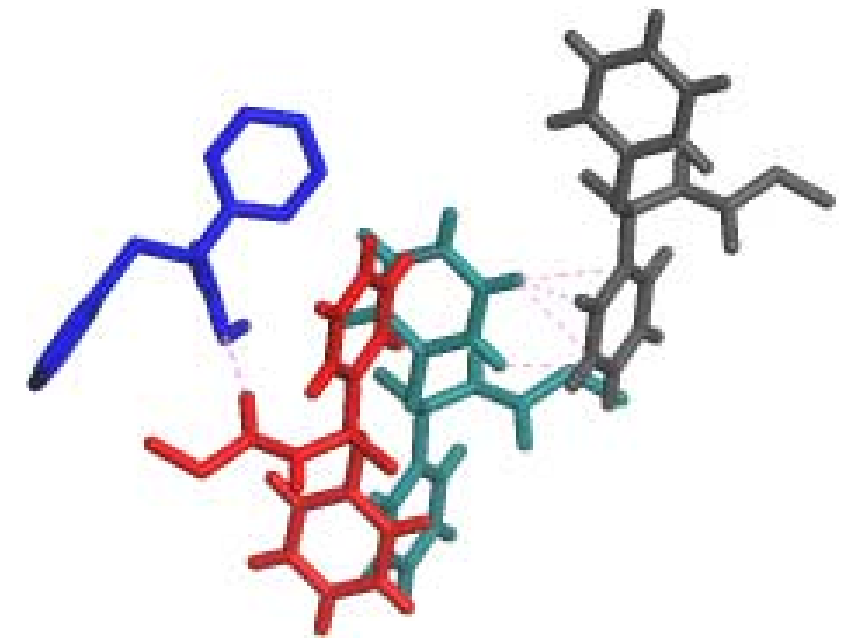

Figure ESI1. A summary of all intermolecular interactions in the crystal structure of $\mathbf{1}$. The interaction between the blue and red molecules is the moderate $\mathrm{N}-\mathrm{H} \bullet \bullet \bullet \mathrm{O}$ H-bond within the 1-D chains; the red and green molecules are engaged in a pair of ef interactions (involving four aromatic rings), with the green and grey molecules comprising a single ef contact between adjacent aromatic rings. 
Electronic Supplementary Information

3. Crystal structure of [remacemide][chloride] 2

As a racemic mixture of two remacemide cations is present in the asymmetric unit, one cation [comprising atoms $\mathrm{C}(1)-\mathrm{C}(17)$ ] is denoted cation $\mathbf{2 a}$, the other [atoms $\mathrm{C}\left(1^{\prime}\right)-\mathrm{C}\left(17^{\prime}\right)$ ] is denoted cation $\mathbf{2 b}$. The molecular conformation of the two unique cations in the structure of 2 is comparable (Table 4 manuscript, Figure 3 manuscript).

The two-dimensional network formed by the nine hydrophilic interactions (Figure ESI2) lies parallel to the $a b$-plane (a schematic is shown in Figure ESI3). The complex structure may be described as a ladder, with three 'struts' made up of alternating, zig-zag, $\mathrm{N}-\mathrm{H} \bullet \bullet \bullet \mathrm{Cl}$ contacts (first chain $=\mathrm{H}$-bonds $1+2$, the second $=4+5$, and the third $=6+8$ ). The 'rungs' are less clearly identified, as H-bonds 3, 7, and 9 are all found between the chain axes. Using graph set analysis to describe the structure of 2 (where the above individual H-bonds constitute the different first level graph sets) highlights this point (Table $\underline{E S 1})$. The three second level graph set motifs which propagate throughout the structure are $\mathrm{C}_{2}^{1}(4)$, $C_{2}^{1}(4)$ and $C_{2}^{2}(9)$ respectively, whilst the remaining 20 interactions are discrete entities.

Table ESI1. Unitary (first level, on-diagonal) and binary (second level, off-diagonal) graph sets for the H-bonds observed in the structure of 2

\begin{tabular}{|l|l|l|l|l|l|l|l|l|}
\hline & 1 & 2 & 3 & 4 & 5 & 6 & 8 & 9 \\
\hline 1 & $D_{1}^{1}(2)$ & & & & & & & \\
\hline 2 & $C_{2}^{1}(4)$ & $D_{1}^{1}(2)$ & & & & & & \\
\hline 3 & $D_{2}^{2}(5)$ & $D_{2}^{2}(5)$ & $D_{1}^{1}(2)$ & & & & & \\
\hline 4 & - & - & $D_{2}^{1}(3)$ & $D_{1}^{1}(2)$ & & & & \\
\hline 5 & - & - & $D_{2}^{1}(3)$ & $C_{2}^{1}(4)$ & $D_{1}^{1}(2)$ & & & \\
\hline 6 & $D_{2}^{2}(7)$ & $D_{2}^{2}(7)$ & $D_{2}^{2}(7)$ & $D_{2}^{2}(5)$ & $D_{2}^{2}(5)$ & $D_{1}^{1}(2)$ & & \\
\hline 8 & $D_{2}^{2}(8)$ & $D_{2}^{2}(8)$ & $D_{2}^{2}(8)$ & $D_{2}^{2}(7)$ & $D_{2}^{2}(7)$ & $C_{2}^{2}(9)$ & $D_{1}^{1}(2)$ & \\
\hline 9 & $D_{2}^{1}(3)$ & $D_{2}^{1}(3)$ & - & $D_{2}^{2}(8)$ & $D_{2}^{2}(8)$ & $D_{2}^{2}(8)$ & $D_{2}^{2}(6)$ & $D_{1}^{1}(2)$ \\
\hline
\end{tabular}



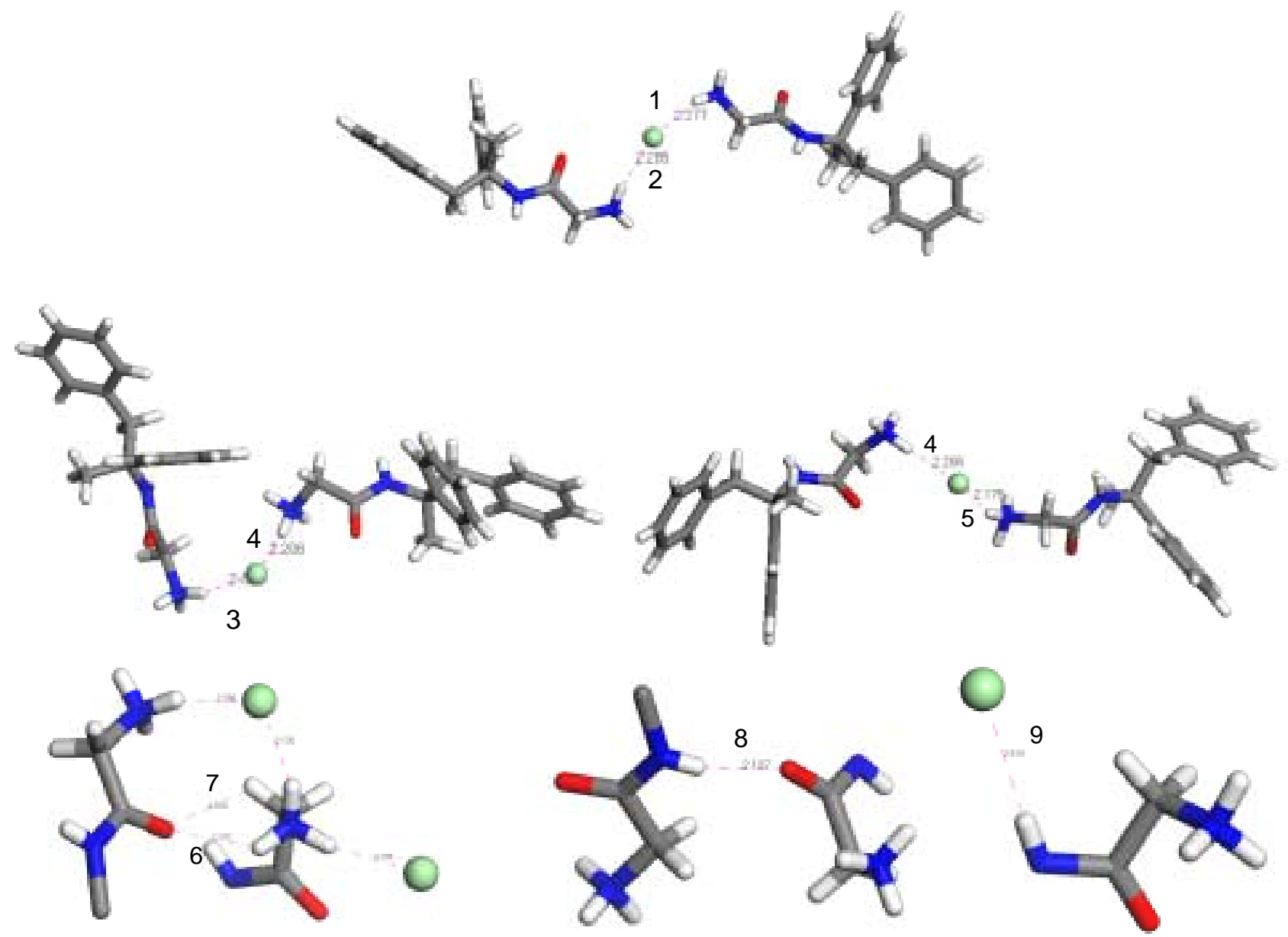

Figure ESI2. The individual H-bonds formed in the structure of 2, with the numbering scheme as described in the text. Geometric details for the contacts are summarized in Table 5 manuscript. 
Electronic Supplementary Information

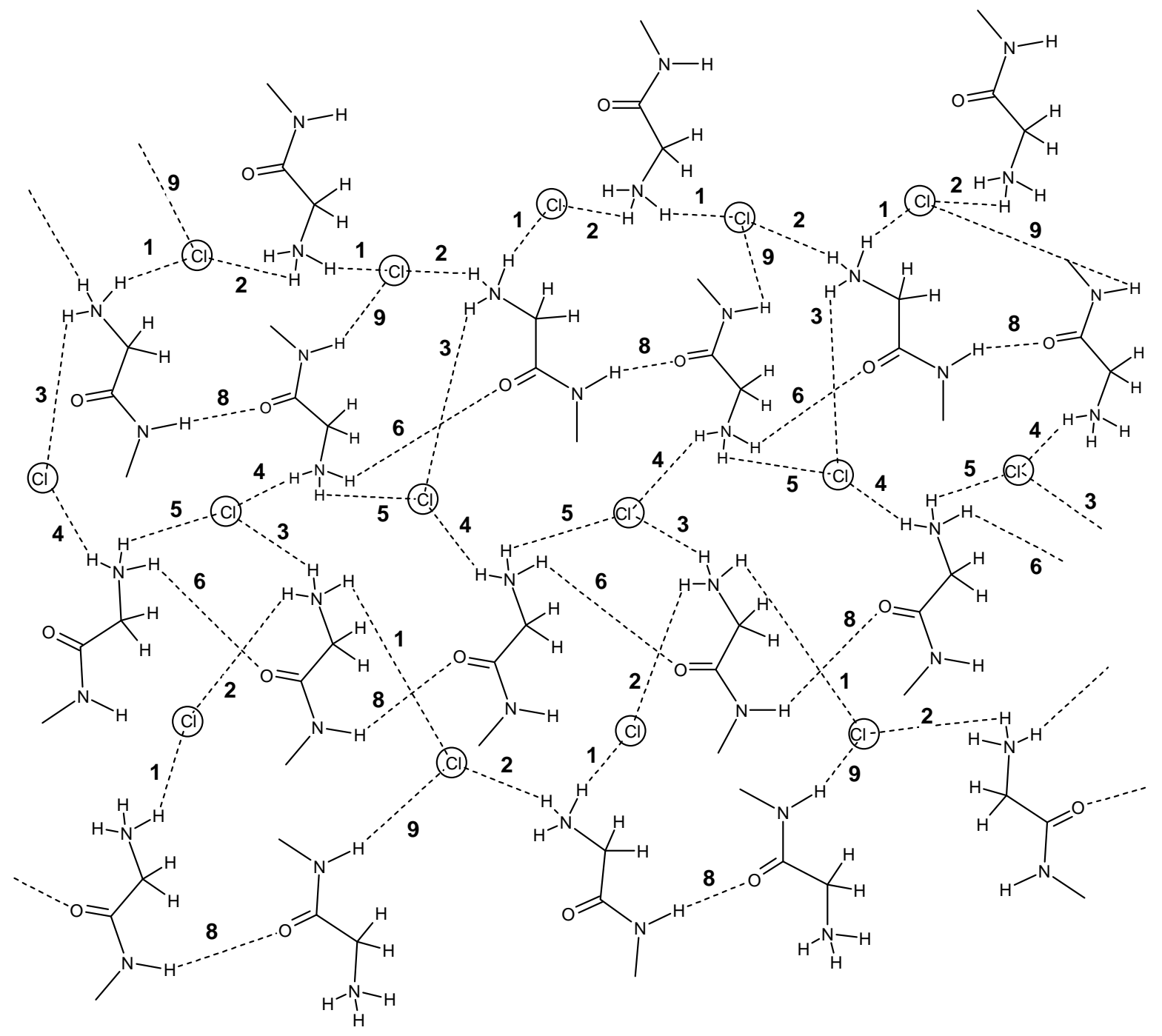

Figure ESI3. Schematic showing the individual interactions that comprise the 2D layer of H-bonds in the structure of 2 . The numbers correspond to the individual contacts described in the text. For clarity, Hbond $7(\mathrm{C}-\mathrm{H} \bullet \bullet \bullet \mathrm{O})$ has been omitted and only the hydrophilic end of each remacemide cation is shown. 
Electronic Supplementary Information

\section{Crystal structure of [remacemide][nitrate] $\mathbf{3}$}

A total of ten different intermolecular H-bonds are observed in the structure of $\mathbf{3}$, involving the amine and amide protons as donors and either the nitrate or, in one instance only, the amide carbonyl as acceptor (Figure ESI4). The first bond detailed in Table 5 (H-bond 1) is an $\mathrm{N}-\mathrm{H} \bullet \bullet \bullet \mathrm{O}$ interaction between the protonated amine group of one cation and the amide carbonyl O-atom of second cation. Two nearest-neighbor molecules participate in a centrosymmetric dimer of these contacts, giving a $\mathrm{R}_{2}^{2}(10)$ motif. The proton involved in $\mathrm{H}$-bond 1 is also closely situated to an $\mathrm{O}$-atom of the nitrate anion $[\mathrm{O}(2)]$. However, the narrow angle ( $\mathrm{ca} .99^{\circ}$ ) suggests that this short separation (H-bond 2) is a consequence of the crystal packing rather than being an energetically stabilizing interaction. Nevertheless, the geometric parameters for H-bond 2 classify it as a weak H-bond, or a purely electrostatic interaction. Each of the nitrate anion O-atoms act as H-bond acceptors in two different interactions. The first instance described is an asymmetric three-centered H-bond involving one proton from an amine group and $\mathrm{O}$-atoms $\mathrm{O}(2)(\mathrm{H}$-bond 3) and $\mathrm{O}(3)(\mathrm{H}$-bond 4). The asymmetry results in one well directed moderate H-bond, with the longer interaction classified as a weak interaction. The close proximity of the protonated amine group to the nitrate anions also results in a short $\mathrm{N}-\mathrm{H} \bullet \bullet \bullet \mathrm{N}$ separation which may be considered to have some weakly stabilizing contribution to the crystal lattice (H-bond 10). The second example of a three-centered $\mathrm{N}-\mathrm{H} \bullet \bullet \bullet \mathrm{O}$ motif combines $\mathrm{H}$-bonds 5 and 6 with $\mathrm{H}$-bond 7 further contributing to the interaction. Finally, a third example of the same three-centered motif is observed to involve the amide $\mathrm{H}$-atom (H-bonds 8 and 9).

The three-centered interactions are shown as small rings [e.g. $R_{1}^{2}(3)$, Table ESI2] which in turn form larger rings [e.g. $\mathrm{R}_{2}^{2}(6)$ ] when combined with additional H-bonds involving an adjacent proton from the same donor amine group. There are several large ring descriptors $\left[R_{n}^{n}(x)\right.$ where $n=2, x=14 ; n=4, x=$ 16 or 18], all of which refer to one motif, where the ring size (x) depends on the exact composition of the ring. 
Electronic Supplementary Information

Table ESI2. Unitary (first level, on-diagonal) and binary (second level, off-diagonal) graph sets for the H-bonds observed in the structure of $\mathbf{3}$

\begin{tabular}{|l|l|l|l|l|l|l|l|l|l|l|}
\hline & 1 & 2 & 3 & 4 & 5 & 6 & 7 & 8 & 9 & 10 \\
\hline 1 & $\mathrm{R}_{2}^{2}(10)$ & & & & & & & & & \\
\hline 2 & $\mathrm{D}_{3}^{2}(8)$ & $\mathrm{D}_{1}^{1}(2)$ & & & & & & & & \\
\hline 3 & $\mathrm{D}_{3}^{3}(10)$ & $\mathrm{R}_{2}^{1}(4)$ & $\mathrm{D}_{1}^{1}(2)$ & & & & & & & \\
\hline 4 & $\mathrm{D}_{3}^{3}(10)$ & $\mathrm{R}_{2}^{2}(6)$ & $\mathrm{R}_{1}^{2}(4)$ & $\mathrm{D}_{1}^{1}(2)$ & & & & & & \\
\hline 5 & $\mathrm{D}_{3}^{3}(10)$ & $\mathrm{C}_{2}^{1}(4)$ & $\mathrm{C}_{2}^{1}(4)$ & $\mathrm{C}_{2}^{2}(6)$ & $\mathrm{D}_{1}^{1}(2)$ & & & & & \\
\hline 6 & $\mathrm{D}_{3}^{3}(10)$ & $\mathrm{C}_{2}^{2}(6)$ & $\mathrm{C}_{2}^{2}(6)$ & $\mathrm{C}_{2}^{2}(6)$ & $\mathrm{R}_{1}^{2}(4)$ & $\mathrm{D}_{1}^{1}(2)$ & & & & \\
\hline 7 & $\mathrm{D}_{3}^{3}(10)$ & $\mathrm{C}_{2}^{2}(5)$ & $\mathrm{R}_{4}^{4}(18)$ & $\mathrm{C}_{2}^{2}(5)$ & $\mathrm{R}_{1}^{2}(3)$ & $\mathrm{R}_{1}^{2}(3)$ & $\mathrm{D}_{1}^{1}(2)$ & & & \\
\hline 8 & $\mathrm{D}_{3}^{3}(10)$ & $\mathrm{R}_{4}^{4}(18)$ & $\mathrm{R}_{4}^{4}(18)$ & $\mathrm{R}_{2}^{2}(14)$ & $\mathrm{C}_{2}^{2}(9)$ & $\mathrm{C}_{2}^{2}(9)$ & $\mathrm{C}_{2}^{2}(8)$ & $\mathrm{D}_{1}^{1}(2)$ & & \\
\hline 9 & $\mathrm{D}_{3}^{3}(10)$ & $\mathrm{R}_{4}^{4}(18)$ & $\mathrm{R}_{1}^{2}(3)$ & $\mathrm{R}_{4}^{4}(18)$ & $\mathrm{C}_{2}^{2}(9)$ & $\mathrm{C}_{2}^{1}(7)$ & $\mathrm{C}_{2}^{2}(8)$ & $\mathrm{R}_{1}^{2}(4)$ & $\mathrm{D}_{1}^{1}(2)$ & \\
\hline 10 & $\mathrm{D}_{3}^{3}(10)$ & $\mathrm{R}_{2}^{2}(5)$ & $\mathrm{C}_{2}^{2}(5)$ & $\mathrm{R}_{1}^{2}(3)$ & $\mathrm{C}_{2}^{2}(5)$ & $\mathrm{C}_{2}^{2}(5)$ & $\mathrm{C}_{2}^{1}(4)$ & $\mathrm{R}_{4}^{4}(16)$ & $\mathrm{R}_{4}^{4}(16)$ & $\mathrm{D}_{1}^{1}(2)$ \\
\hline
\end{tabular}


Electronic Supplementary Information
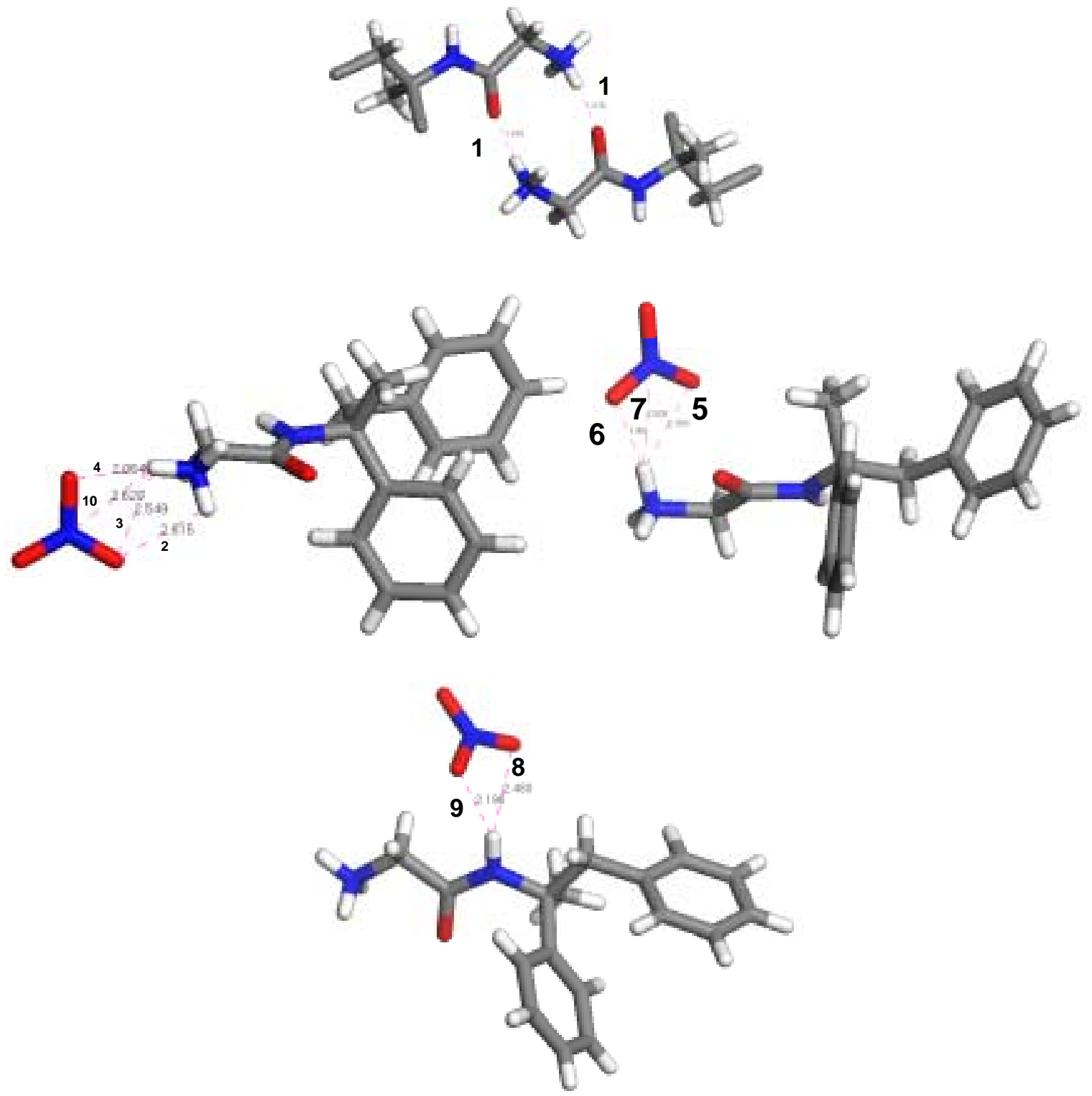

Figure ESI4. The individual H-bonds formed in the structure of $\mathbf{3}$, with the numbering scheme as described in the text. Geometric details for the contacts are summarized in Table 5 manuscript. 
Electronic Supplementary Information

\section{Crystal structure of [remacemide][acetate] 4}

The interaction (H-bond 4) between an amide carbonyl and an amine group from a second cation is centrosymmetric. Consequently, the contact combines to yield a $R_{2}^{2}(10)$ ring motif (Figure ESI5) and precludes homologous interactions between amide moieties.

The hydrophilic regions in the structure of $\mathbf{4}$ form layers in the $b c$-plane. Extending in the $c$-direction, an $\mathrm{R}_{3}^{4}(16)$ motif incorporating H-bonds 1, 2 and 3 (Figure ESI6) alternates with the centrosymmetric

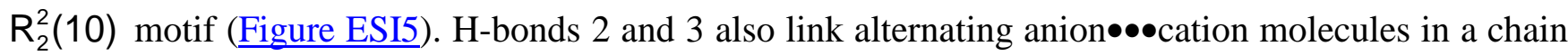
extending in the $b$-direction. The binary level motifs involving $\mathrm{H}$-bonds 1,2 and 3 are all chain operations (Table ESI3).

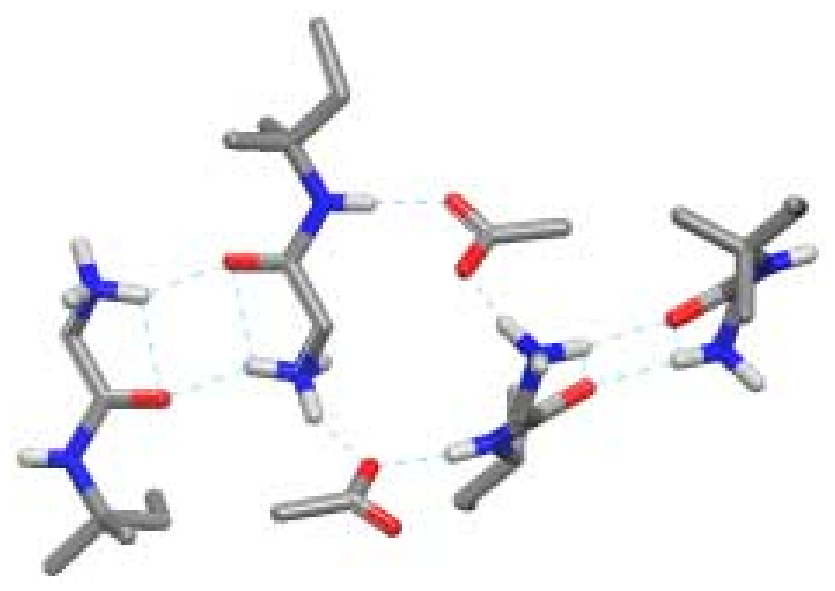

Figure ESI5. Ring motifs in the hydrophilic layer of 4 . The striking similarity between this $R_{2}^{2}(10)+$ $R_{3}^{4}(16)$ combination in 4 and the $R_{2}^{2}(10)+R_{4}^{4}(18)$ combination in 3 may stem from the comparable volumes and geometries of acetate and nitrate that enables them to participate in comparable H-bonding motifs with remacemide.

Table ESI3. Unitary (first level, on-diagonal) and binary (second level, off-diagonal) graph sets for the H-bonds observed in the structure of 4

\begin{tabular}{|l|l|l|l|l|}
\hline & 1 & 2 & 3 & 4 \\
\hline 1 & $D_{1}^{1}(2)$ & & & \\
\hline 2 & $C_{2}^{2}(9)$ & $D_{1}^{1}(2)$ & & \\
\hline 3 & $C_{2}^{1}(7)$ & $C_{2}^{2}(6)$ & $D_{1}^{1}(2)$ & \\
\hline 4 & $D_{3}^{3}(12)$ & $D_{3}^{3}(10)$ & $D_{3}^{3}(10)$ & $R_{2}^{2}(10)$ \\
\hline
\end{tabular}


Electronic Supplementary Information
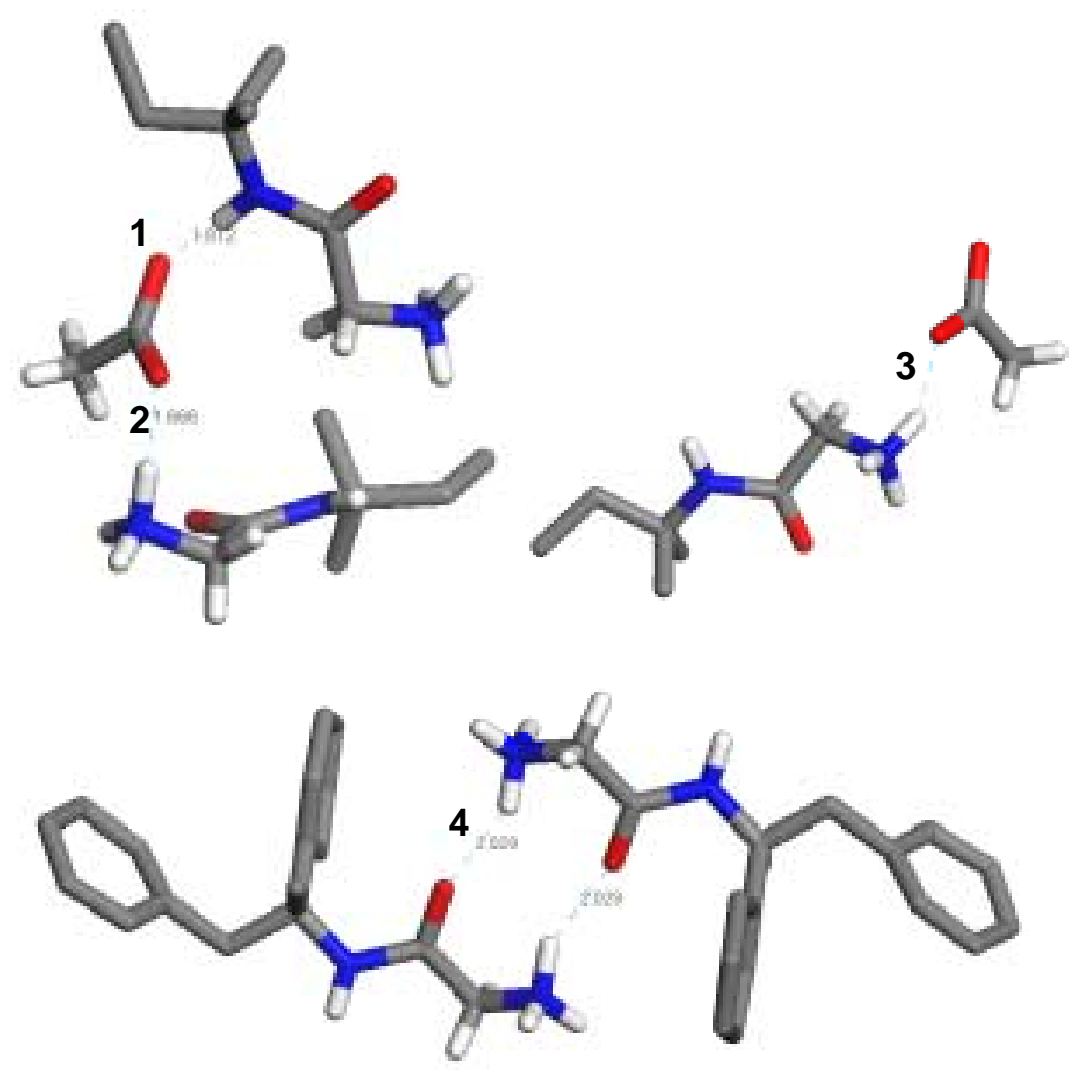

Figure ESI6. The individual hydrogen bonds formed in the structure of 4, with the numbering scheme as described in the text. Geometric details for the contacts are summarized in Table 5 manuscript. 
Electronic Supplementary Information

\section{Crystal structure of [remacemide][hemifumarate] 5}

The two remacemide molecules in the asymmetric unit differ with respect to the relative orientation of the aromatic rings (one molecule anti, the other syn; Figure 3 manuscript and Table 4 manuscript), implying that the aromatic rings of the two cations participate in different local intermolecular interactions. For ease of discussion, one cation (comprising atoms $\mathrm{C} 1-\mathrm{C} 17$ ) is denoted cation 5a, the other (atoms $\mathrm{C} 1$ '-C17') is denoted cation $5 \mathrm{~b}$.

Two analogous $\mathrm{O}-\mathrm{H} \bullet \bullet \bullet \mathrm{O}$ interactions ( $\mathrm{H}$ bonds 1 and 2, Figure ESI7) are observed, linking the carboxylic acid group of one hemifumarate molecule and the anionic carboxylate moiety of a second hemifumarate. These unitary motifs extend to give a $C_{1}^{1}(7)$ chain of anions that runs parallel to the $a$ axis. The O-atoms of the hemifumarate molecules act as H-bond acceptors in a total of five unique intermolecular interactions with remacemide. Four of these contacts (H-bonds 3, 4, 8 and 9, Table 5) involve protonated amine groups as donors, with the fifth interaction (H-bond 7) linking to an amide proton. H-bond 7 is the only interaction involving an amide proton. Finally, H-bonds 5 and 6 are $\mathrm{N}-\mathrm{H} \bullet \bullet \bullet \mathrm{O}$ contacts involving amine protons and carbonyl acceptors in remacemide.

The large number of H-bonds yield a wide range of binary motifs in the structure of $\mathbf{5}$. However, in contrast to the many rings formed in the structure of $\mathbf{3}$, the hemifumarate salt is dominated by discrete interactions, with only three extended chain motifs and one ring motif (Table ESI4). The only chain involving different molecular species is a $\mathrm{C}_{2}^{2}(12)$ motif which comprises individual H-bonds 4 and 7. The other binary motif of note is the 10-membered ring formed by H-bonds 5 and 8, which arises from a head-to-tail arrangement of remacemide cations $(\mathbf{5 a}, \mathbf{5} \mathbf{b})$. 
Electronic Supplementary Information

Table ESI4. Unitary (first level, on-diagonal) and binary (second level, off-diagonal) graph sets for the H-bonds observed in the structure of 5

\begin{tabular}{|l|l|l|l|l|l|l|l|l|l|}
\hline & 1 & 2 & 3 & 4 & 5 & 6 & 7 & 8 & 9 \\
\hline 1 & $\mathrm{C}_{1}^{1}(7)$ & & & & & & & & \\
\hline 2 & - & $\mathrm{C}_{1}^{1}(7)$ & & & & & & & \\
\hline 3 & - & $\mathrm{D}_{3}^{3}(12)$ & $\mathrm{D}_{1}^{1}(2)$ & & & & & & \\
\hline 4 & $\mathrm{D}_{3}^{3}(12)$ & - & $\mathrm{D}_{2}^{2}(5)$ & $\mathrm{D}_{1}^{1}(2)$ & & & & & \\
\hline 5 & - & - & $\mathrm{D}_{2}^{2}(5)$ & $\mathrm{D}_{2}^{2}(5)$ & $\mathrm{D}_{1}^{1}(2)$ & & & & \\
\hline 6 & - & $\mathrm{D}_{3}^{3}(12)$ & $\mathrm{D}_{2}^{1}(3)$ & - & $\mathrm{D}_{2}^{2}(7)$ & $\mathrm{D}_{1}^{1}(2)$ & & & \\
\hline 7 & $\mathrm{D}_{3}^{3}(12)$ & - & $\mathrm{D}_{2}^{2}(8)$ & $\mathrm{C}_{2}^{2}(12)$ & $\mathrm{D}_{2}^{2}(8)$ & - & $\mathrm{D}_{1}^{1}(2)$ & & \\
\hline 8 & - & - & $\mathrm{D}_{2}^{2}(7)$ & $\mathrm{D}_{2}^{2}(7)$ & $\mathrm{R}_{2}^{2}(10)$ & $\mathrm{D}_{2}^{2}(5)$ & $\mathrm{D}_{2}^{2}(6)$ & $\mathrm{D}_{1}^{1}(2)$ & \\
\hline 9 & $\mathrm{D}_{3}^{3}(12)$ & - & - & $\mathrm{D}_{2}^{1}(3)$ & $\mathrm{D}_{2}^{2}(7)$ & $\mathrm{D}_{2}^{2}(5)$ & $\mathrm{D}_{2}^{2}(6)$ & $\mathrm{D}_{2}^{2}(5)$ & $\mathrm{D}_{1}^{1}(2)$ \\
\hline
\end{tabular}


Electronic Supplementary Information
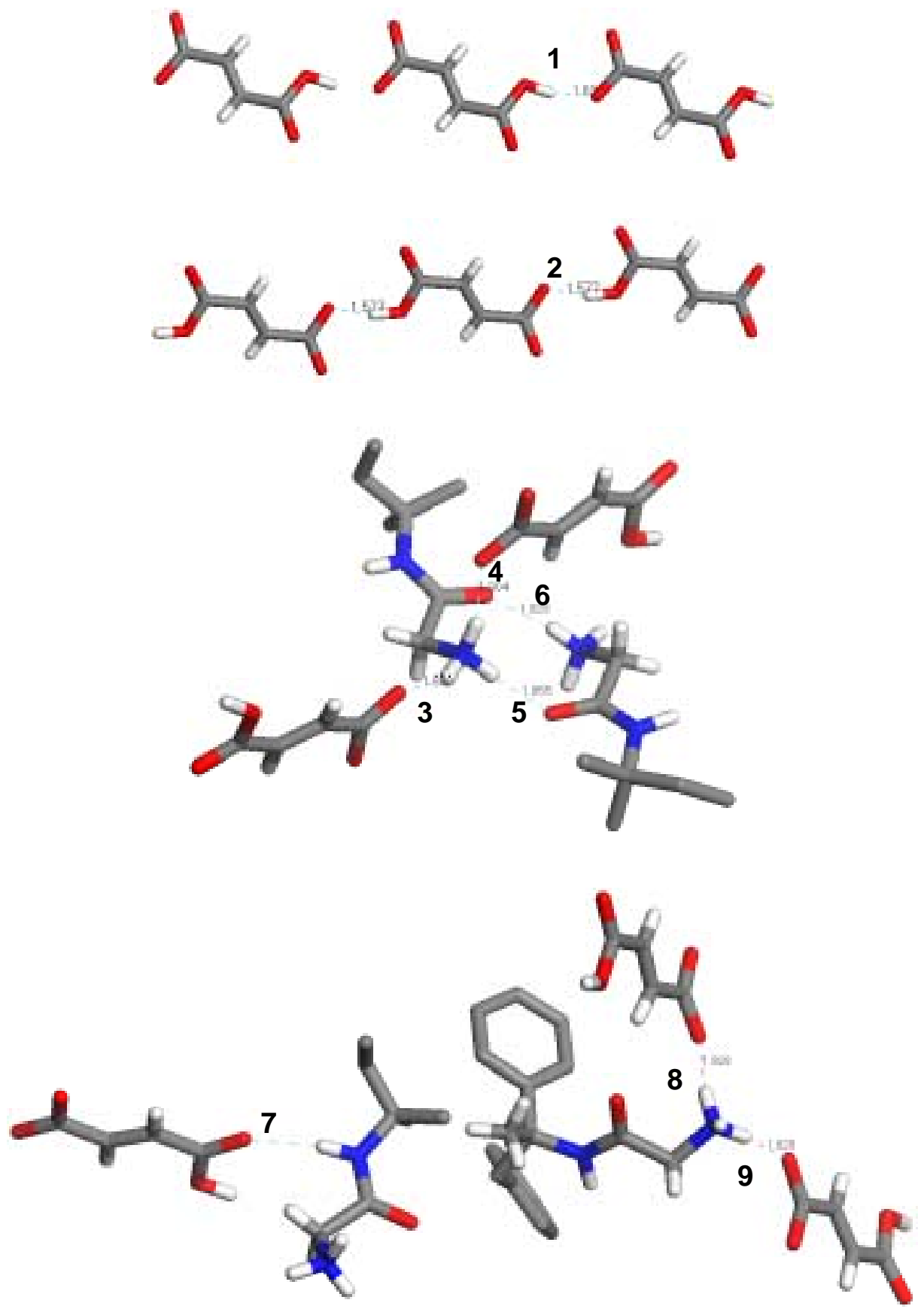

Figure ESI7. The individual H-bonds formed in the structure of $\mathbf{5}$, with the numbering scheme as described in the text. Geometric details for the contacts are summarized in Table 5 manuscript. 


\section{Crystal structure of [remacemide][naphthalene-2-sulphonate] $\bullet 0.4 \mathrm{EtOH} \bullet 0.5 \mathrm{H}_{2} \mathrm{O} 6$}

$\mathrm{H}$-bonds 4 and 5 (Figure ESI8) are $\mathrm{N}-\mathrm{H} \bullet \bullet \bullet \mathrm{O}$ interactions between the protonated amine group of one remacemide molecule and the sulphonate $\mathrm{O}$-atoms of an anion. The proton involved in H-bond 5 also forms a longer contact to the sulphonate moiety of a second, symmetry related neighboring anion $(\mathrm{H}-$ bond 6). These three interactions form three different ring motifs: H-bonds 5 and 6 link two cations and two anions in a centrosymmetric binary $R_{2}^{2}(4)$ motif; H-bonds 4 and 5 form a binary $R_{2}^{2}(6)$ motif, with H-bonds 4 and 6 forming a larger $R_{4}^{4}(12)$ set of interactions. The third proton of the above amine group forms two contacts with the water and $\mathrm{EtOH}$ molecules (H-bonds 7 and 8).

With this number of H-bonds, it is somewhat surprising that there are so few extended binary motifs (Table ESI5). Only four rings are observed, and one chain motif. Three of the rings are described above, with the fourth $\mathrm{R}_{4}^{4}(12)$ motif combining H-bonds 10 and 12 .

Each O-atom of the sulphonate group is disordered between high occupancy (79\%) and low occupancy sites. The high occupancy $\mathrm{O}(6), \mathrm{O}(7)$ and $\mathrm{O}(8)$ atoms accept a total of four H-bonds (Table 5 manuscript), specifically H-bond 12 [to $\mathrm{O}(6)$ ], H-bonds 2 and 3 [to $\mathrm{O}(7)$ ] and H-bond 10 [to $\mathrm{O}(8)$ ]. In

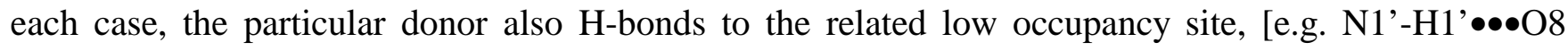
$\left.(79 \%)=2.04 \AA ; \mathrm{N} 1{ }^{\prime}-\mathrm{H} 1{ }^{\prime} \bullet \bullet \bullet \mathrm{O} 8 \mathrm{~A}(21 \%)=2.02 \AA\right]$. The difference in H-bond distance for each related pair is small (RMS $=0.17 \AA$, summed across all four pairs of $\mathrm{H}$-bonds). Thus, the sulphonate group is able to adopt an entropically favorable disordered configuration while, at the same time, preserving the favorable H-bonding arrangement and avoiding the creation of any unfavorable short contacts. 
Electronic Supplementary Information

Table ESI5. Unitary (first level, on-diagonal) and binary (second level, off-diagonal) graph sets for the H-bonds observed in the structure of 6

\begin{tabular}{|l|l|l|l|l|l|l|l|l|l|l|l|l|l|}
\hline & 1 & 2 & 3 & 4 & 5 & 6 & 7 & 8 & 9 & 10 & 11 & 12 & 13 \\
\hline 1 & $\mathrm{D}_{1}^{1}(2)$ & & & & & & & & & & & & \\
\hline 2 & $\mathrm{D}_{2}^{2}(5)$ & $\mathrm{D}_{1}^{1}(2)$ & & & & & & & & & & & \\
\hline 3 & - & $\mathrm{D}_{2}^{1}(3)$ & $\mathrm{D}_{1}^{1}(2)$ & & & & & & & & & & \\
\hline 4 & $\mathrm{D}_{2}^{1}(3)$ & - & - & $\mathrm{D}_{1}^{1}(2)$ & & & & & & & & & \\
\hline 5 & $\mathrm{D}_{2}^{2}(5)$ & - & - & $\mathrm{R}_{2}^{2}(6)$ & $\mathrm{D}_{1}^{1}(2)$ & & & & & & & & \\
\hline 6 & $\mathrm{D}_{2}^{2}(5)$ & - & - & $\mathrm{R}_{4}^{4}(12)$ & $\mathrm{R}_{2}^{2}(4)$ & $\mathrm{D}_{1}^{1}(2)$ & & & & & & & \\
\hline 7 & $\mathrm{D}_{2}^{2}(4)$ & $\mathrm{D}_{2}^{2}(4)$ & - & $\mathrm{D}_{2}^{2}(5)$ & $\mathrm{D}_{2}^{2}(5)$ & $\mathrm{D}_{2}^{2}(5)$ & $\mathrm{D}_{1}^{1}(2)$ & & & & & & \\
\hline 8 & - & - & $\mathrm{D}_{2}^{2}(4)$ & $\mathrm{D}_{2}^{2}(5)$ & $\mathrm{D}_{2}^{2}(5)$ & $\mathrm{D}_{2}^{2}(5)$ & $\mathrm{D}_{1}^{2}(3)$ & $\mathrm{D}_{1}^{1}(2)$ & & & & & \\
\hline 9 & - & - & - & $\mathrm{D}_{2}^{2}(8)$ & $\mathrm{D}_{2}^{2}(8)$ & $\mathrm{D}_{2}^{2}(8)$ & $\mathrm{D}_{2}^{2}(8)$ & $\mathrm{D}_{2}^{2}(8)$ & $\mathrm{D}_{1}^{1}(2)$ & & & & \\
\hline 10 & - & $\mathrm{D}_{2}^{2}(5)$ & $\mathrm{D}_{2}^{2}(5)$ & - & - & - & - & - & $\mathrm{D}_{2}^{2}(7)$ & $\mathrm{D}_{1}^{1}(2)$ & & & \\
\hline 11 & $\mathrm{D}_{2}^{2}(5)$ & - & - & $\mathrm{D}_{2}^{2}(5)$ & $\mathrm{D}_{2}^{2}(5)$ & $\mathrm{D}_{2}^{2}(5)$ & - & - & $\mathrm{D}_{2}^{2}(7)$ & $\mathrm{D}_{2}^{2}(5)$ & $\mathrm{D}_{1}^{1}(2)$ & & \\
\hline 12 & - & $\mathrm{D}_{2}^{2}(5)$ & $\mathrm{D}_{2}^{2}(5)$ & - & - & - & - & - & $\mathrm{D}_{2}^{2}(7)$ & $\mathrm{R}_{4}^{4}(12)$ & $\mathrm{D}_{2}^{2}(5)$ & $\mathrm{D}_{1}^{1}(2)$ & \\
\hline 13 & - & - & - & $\mathrm{D}_{2}^{2}(7)$ & $\mathrm{D}_{2}^{2}(7)$ & $\mathrm{D}_{2}^{2}(7)$ & $\mathrm{D}_{2}^{2}(7)$ & $\mathrm{D}_{2}^{2}(7)$ & $\mathrm{C}_{2}^{2}(8)$ & $\mathrm{D}_{2}^{2}(8)$ & $\mathrm{D}_{2}^{2}(8)$ & $\mathrm{D}_{2}^{2}(8)$ & $\mathrm{D}_{1}^{1}(2)$ \\
\hline
\end{tabular}



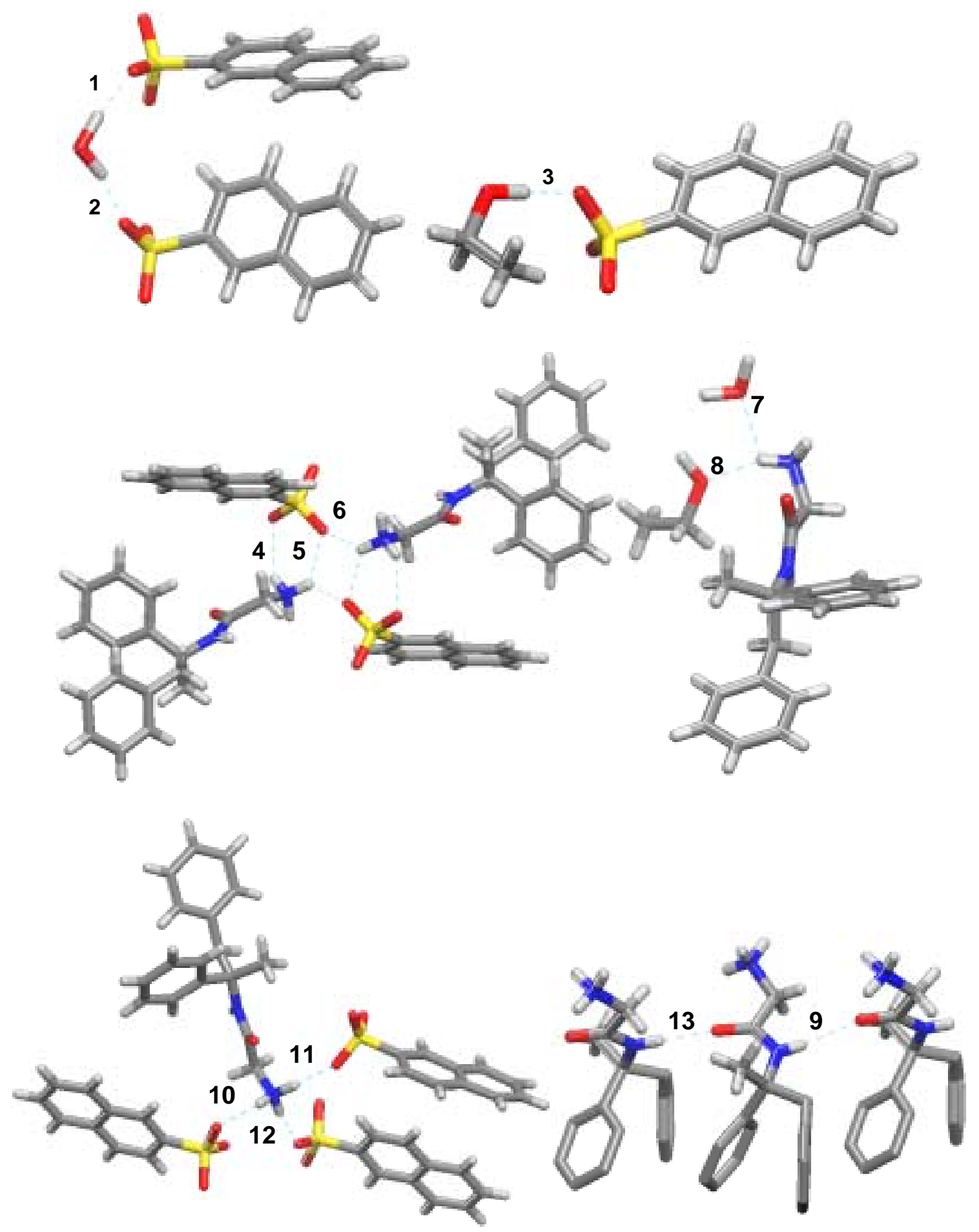

Figure ESI8. The individual H-bonds formed in the structure of $\mathbf{6}$, with the numbering scheme as described in the text. Geometric details for the contacts are summarized in Table 5 manuscript. 
Electronic Supplementary Information

\section{Crystal structure of [remacemide][1-hydroxynaphthalene-2-carboxylate] 7}

The geometry of the xinafoate anion is as expected, with the alcohol and acid moieties in the plane of the naphthalene ring and connected by an intramolecular $\mathrm{H}$-bond (H-bond 1, Figure ESI9). A further four intermolecular H-bonds are observed in the structure of $\mathbf{7}$ and are described in Table 5 manuscript, with the graph sets given in Table ESI6.

Table ESI6. Unitary (first level, on-diagonal) and binary (second level, off-diagonal) graph sets for the H-bonds observed in the structure of 7

\begin{tabular}{|l|l|l|l|l|l|}
\hline & 1 & 2 & 3 & 4 & 5 \\
\hline 1 & $\mathrm{~S}_{1}^{1}(6)$ & & & & \\
\hline 2 & - & $\mathrm{C}_{1}^{1}(5)$ & & & \\
\hline 3 & - & $\mathrm{D}_{3}^{3}(10)$ & $\mathrm{D}_{1}^{1}(2)$ & & \\
\hline 4 & - & $\mathrm{D}_{3}^{3}(10)$ & $\mathrm{C}_{2}^{2}(6)$ & $\mathrm{D}_{1}^{1}(2)$ & \\
\hline 5 & - & $\mathrm{D}_{3}^{3}(12)$ & $\mathrm{C}_{2}^{2}(11)$ & $\mathrm{C}_{2}^{2}(11)$ & $\mathrm{D}_{1}^{1}(2)$ \\
\hline
\end{tabular}



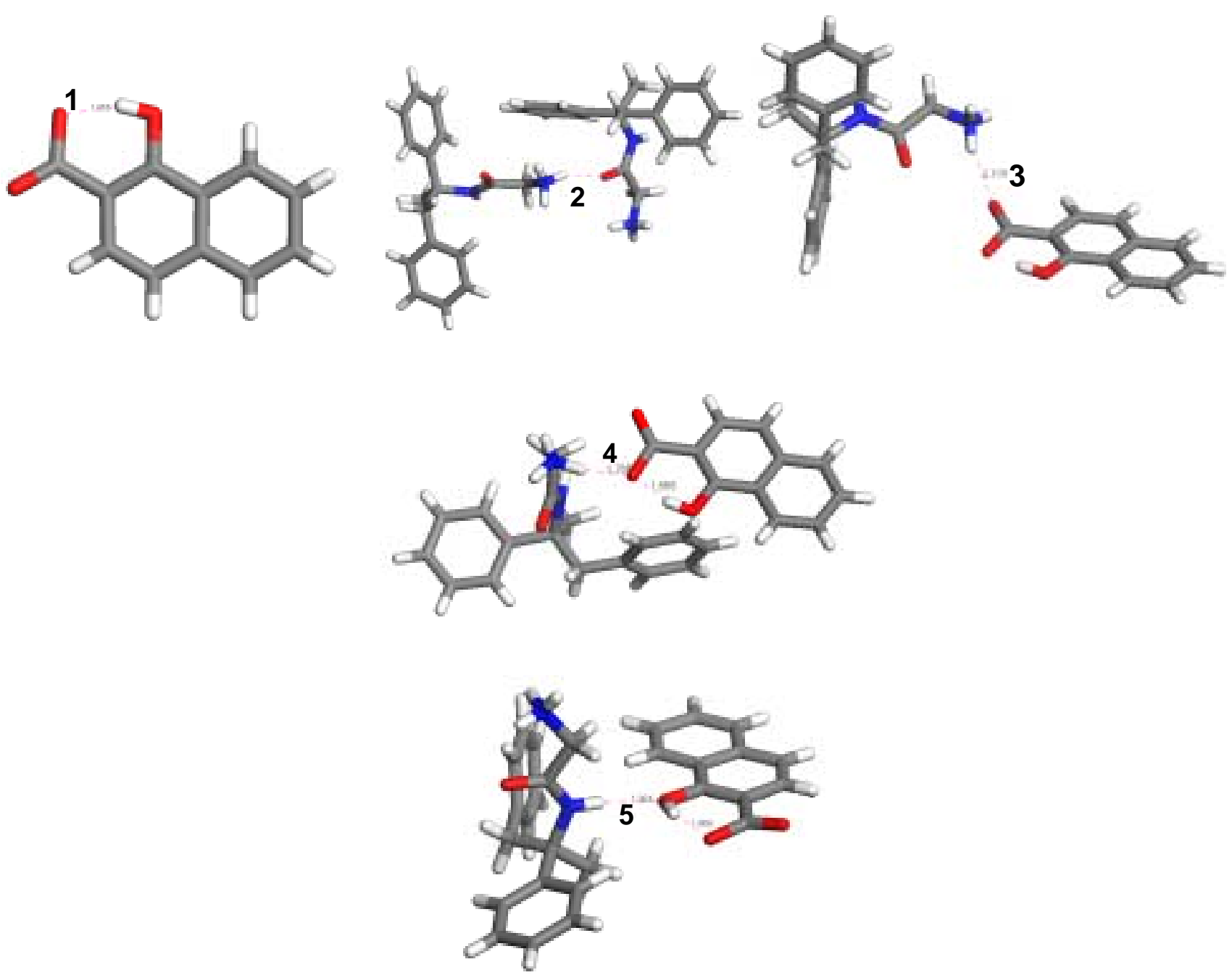

Figure ESI9. The individual hydrogen bonds formed in the structure of 7, with the numbering scheme as described in the text. Geometric details for the contacts are summarised in Table 5 manuscript. 